\title{
GESTÃO ESCOLAR DEMOCRÁTICA: proposições legais no contexto neoliberal brasileiro
}

\author{
Pérsida da Silva Ribeiro Miki \\ Carlos César Macêdo Maciel
}

\section{Resumo}

O presente Artigo Científico tem como objetivo compreender o processo histórico que protagonizou a democratização do ambiente escolar no contexto brasileiro marcado pelo neoliberalismo. Trata-se de uma análise bibliográfica, de natureza qualitativa, e que vem promover o incessante debate em torno da gestão escolar democrática, onde a (des) construção de valores sociais, políticos, econômicos e culturais se faz necessária. Buscou-se realizar uma leitura minuciosa de quatro principais documentos que legalizam a educação brasileira: a Constituição Federal de 1988, a Lei de Diretrizes e Bases da Educação Nacional de 20 de dezembro de 1996 e o Plano Nacional de Educação (2001-2010 e 2014-2024). Assim também, realizouse a leitura das obras de importantes estudiosos e pensadores do fenômeno democrático, tais como Bobbio (1987), Chauí (1997) e Paro (2002). Um fator relevante a ser apresentado neste trabalho é que se faz necessário sair do comodismo para que a mudança aconteça efetivamente. A democratização requer participação coletiva, uma vez que sem essa participação é impossível mencionar que a democracia ocorreu de fato.

Palavras-chave: gestão escolar; democracia; neoliberalismo; processo histórico.

\section{DEMOCRATIC SCHOOL MANAGEMENT: legal proposals in the brazilian neoliberal context}

\section{Abstract}

This Scientific Article aims to understand the historical process that led to the democratization of the school environment in the Brazilian context marked by neoliberalism. This is a bibliographic analysis, of a qualitative nature, which promotes the incessant debate around democratic school management, where the (de) construction of social, political, economic and cultural values is necessary. We sought to carry out a thorough reading of four main documents that legalize Brazilian education: the Federal Constitution of 1988 and the Law of Guidelines, Bases for National Education of December 20, 1996 and the National Education Plan (2001-2010 and 2014-2024). Thus, the works of important scholars and thinkers of the democratic phenomenon, such as Bobbio (1987), Chauí (1997) and Paro (2002). A relevant factor to be presented in this work is that it is necessary to get out of self-indulgence for change to happen effectively. Democratization requires collective participation, since without such participation it is impossible to mention that democracy actually took place.

Keywords: school management; democracy; neoliberalism; historical process.

\section{GESTIÓN DE LA ESCUELA DEMOCRÁTICA: propuestas legales en el contexto neoliberal brasileño}

Resumen

Este artículo científico tiene como objetivo comprender el proceso histórico que condujo a la democratización del entorno escolar en el contexto brasileño marcado por el neoliberalismo. Este es un análisis bibliográfico, de naturaleza cualitativa, que promueve el debate incesante en torno a la gestión escolar 
democrática, donde es necesaria la (des) construcción de valores sociales, políticos, económicos y culturales. Intentamos llevar a cabo una lectura exhaustiva de cuatro documentos principales que legalizan la educación brasileña: la Constitución Federal de 1988, la Ley de Directrices y Bases para la Educación Nacional del 20 de diciembre de 1996, y el Plan Nacional de Educación (2001-2010 y 2014-2024). Así, los trabajos de importantes eruditos y pensadores del fenómeno democrático, como Bobbio (1987), Chauí (1997) y Paro (2002). Un factor relevante que se presentará en este trabajo es que es necesario salir de la autocomplacencia para que el cambio ocurra de manera efectiva. La democratización requiere la participación colectiva, ya que sin esa participación es imposible mencionar que la democracia realmente se llevó a cabo.

Palabras clave: gestión escolar; democracia; neoliberalismo; proceso histórico.

\section{INTRODUÇÃO}

Considerada um espaço de socialização do conhecimento, a escola pública precisa concentrar-se nos valores da gestão democrática que influenciam o processo de ensino de modo direto. Essencialmente, a organização de uma escola, pautada na democracia transcorre pelo envolvimento da comunidade escolar, traz em sua composição avaliativa, discentes, pais e/ou alunos e funcionários no âmbito das decisões tomadas de forma conjunta. Argumenta-se com o envolvimento participativo e o compromisso de todos os protagonistas da atividade pedagógica e torna possível uma ratificação das transformações pelas quais uma instituição de ensino vem atravessando no decorrer da história.

No Brasil, a temática da Gestão Democrática Escolar vem abrindo as portas para novas pesquisas no âmbito da educação a partir dos anos 1990, sendo proveniente da abertura política e da elaboração e aprovação da Constituição Federal de 1988, mantendo relações próximas com a Lei de Diretrizes e Bases da Educação Nacional 9394/96 em 20 de dezembro de 1996, assim como o Plano Nacional de Educação (2001-2010 e 2014-2024), em suas prescrições.

Numa circunstância histórica marcada pelo egoísmo individualista, a burocracia e a centralização do poder, o estudo a respeito de melhores condições para superar esta conjuntura assume enorme relevância política e social. Compreende-se que a sistematização de encontros pedagógicos, envolvimento de todos os partícipes e comissões representativas tornam viável a superação desta realidade institucional. No entanto, essas observações podem conduzir ao conhecimento da força contrária à mudança de paradigmas a respeito desses ambientes e suas particularidades.

Porém, mesmo tendo consciência da complexidade de colocar em prática os princípios democráticos na escola, é inadmissível desconsiderar o debate tendo em vista a superação desta realidade, analisando a educação desenvolvida na escola pública. Desse modo, acredita-se que a qualidade na educação terá progresso ao mesmo tempo em que a gestão escolar estabeleça seus alicerces em valores democráticos, fazendo da instituição de ensino um ambiente de participação e ação coletiva.

Portanto, torna-se imprescindível uma reflexão crítica a respeito das mudanças de natureza econômica, política e social que formam as bases do neoliberalismo e, como resultado disso, vem à tona as políticas contemporâneas de educação. Este artigo inicia analisando a democracia, as aspirações comuns que ela suscita no espaço escolar e na sociedade como um todo, suas colaborações e desafios no mundo marcado pela globalização, tendo consciência dos resultados desta para a atual conjuntura brasileira, possibilitando as políticas de caráter neoliberal. 


\section{GESTÃO DEMOCRÁTICA: MUDANÇAS PARADIGMÁTICAS}

A gestão democrática da escola é um assunto que foi considerado inverossímil em uma época precedente à contemporaneidade, e que foi imensamente assinalada pelos regimes autoritários que governaram o Brasil entre os anos 1960 a 1980. Essa circunstância se configurou pela falta de participação coletiva da população, na qual conseguisse policiar os serviços públicos e com eles contribuir de maneira significativa. Assim, a gestão escolar baseada no envolvimento e compromisso coletivo, buscando interesses comuns, é compreendida como resultado de um amplo e árduo processo de batalhas e conquistas diárias que há bastante tempo permeiam a escola pública e seus desafios.

Como referência para a descentralização do poder, no bojo da educação, percebeu-se esta particularidade na promulgação do Decreto 19.850, de 11 de abril de 1931 que concebe o Conselho Nacional de Educação e, com o estabelecimento da Constituição de 1934 a respeito da elaboração e implantação dos Conselhos Estaduais de Educação. Apesar deste regulamento não se efetivar de maneira direta nos Estados, a Constituição assevera que a descentralização é profundamente importante para tornar possíveis as decisões que respondam efetivamente às particularidades de cada região brasileira (ROMANELLI, 1984).

A gestão baseada na participação coletiva é parte integrante do que se assentou chamar de democratização ou construção da autonomia da escola, em face dos seus desafios e contradições cotidianas. Nas palavras de Touraine (1996, p. 64) a democracia "como o meio institucional favorável à formação e ação do sujeito não teria sentido concreto se o espírito democrático não penetrasse todos os aspectos da vida social organizada".

Sob esta ótica e compreendendo a asserção de Gestão Democrática do Ensino Público, enquanto instrumento de enorme relevância para o meio escolar, no que tange à garantia e continuidade da democratização, nota-se o quanto essencial é a explicação e a compreensão da LDB n. 9394/96 que determina a gestão no setor público escolar, bem como de sua articulação com o neoliberalismo e suas influências sociais, econômicas e políticas. Este paradigma se apreende dos debates sobre a democratização da gestão escolar, para que os professores voltem a sua atenção às políticas de educação, de maneira a entendê-las criticamente, fazendo uso dos ambientes democráticos determinados, servindo à educação enquanto uma responsabilidade para com a sociedade.

Dessa forma, é importante a contextualização do espaço escolar e o conhecimento de seus dilemas e mudanças em uma realidade comunitária, política e econômica, procurando nessa mesma realidade fundamentos para entender as transformações que ocorrem na escola. Compreende-se que a escola passa por tensões profundas advindas de inúmeros elementos, com a intenção de buscar soluções viáveis aos impasses presentes do meio social na qual está inserida. Precisa-se repensar a missão educativa que presume que a sociedade pode se desenvolver de modo eficaz por meio da educação, pois a educação, e, especialmente a escola, não pode ser compreendida como espaço exclusivo de socialização entre os seres humanos.

A escola pode ser compreendida enquanto um ambiente de propagação do pensamento capitalista que o poder estatal emprega, objetivando, dessa forma, o espírito do capitalismo, bem como pode assumir um caráter adverso às forças hegemônicas. Assim, a instituição de ensino pode ser uma ferramenta manuseada pelas classes dominantes para disseminar princípios igualitários que fomentem a educação como redentora da sociedade, principalmente das classes menos favorecidas. No entanto, ao impugnar a acumulação de capital e a contínua exclusão social, pode-se questionar 
o porquê a escola ser vista como um ambiente de problematização e esclarecimento dos conflitos que a sociedade enfrenta.

Nessa circunstância, a escola nunca assumirá o messianismo, pois nenhum empenho educacional pode, no âmbito social, eliminar compreensões corrosivas e estabelecer a igualdade, mesmo a escola sendo considerada um espaço de enfrentamento de problemas e conquistas de interesses comuns (SNYDERS, 1981). Apesar de compreender que a educação não se traduz como assistencialista, e que a mudança da sociedade precisa analisar criticamente as muitas formas de desigualdade em sua gênese e na divisão social de classes, precisa-se conhecer a força competente que a instituição de ensino possui para indagar sobre estas desigualdades, de maneira a contribuir com o avanço do meio social.

\section{INFLUÊNCIAS NEOLIBERAIS}

Em termos de política econômica, Chomsky (2002) esclarece que o neoliberalismo se trata de uma doutrina socioeconômica amparada em uma onda ideológica desde o início dos anos 1980, que tem como premissa a crença de que os princípios do mercado livre e competitivo levam à ordem econômica mais eficiente e racional. O encolhimento dos diversos papeis do Estado, por meio da privatização de empresas e cortes nas políticas de proteção social, é típico das políticas neoliberais. Harvey (2012) comenta que o neoliberalismo ataca os sindicatos, com o objetivo de aumentar a liberdade empresarial. Não é simplesmente uma resposta ao fracasso do keynesianismo; também se baseia em certas mudanças nos fundamentos materiais da economia capitalista, possibilitadas pela tecnologia da informação, que contribuem para a revitalização da economia capitalista, em particular no domínio financeiro. Ainda, segundo o autor, o neoliberalismo é fundamentalmente uma reversão das tendências em ação no capitalismo, desde o final do século XIX. Essas visavam a regulação do mercado livre competitivo em três áreas: 1) a formação de capital monopolista; 2) o crescimento dos sindicatos; e 3) a crescente intervenção do Estado, cujas formas sucessivas têm sido o imperialismo, sua estabilização no sistema mundial da Guerra Fria, Keynesianismo e o Estado de bem-estar. Assim, o estado neoliberal tende a enfraquecer o Estado Nacional, incorporando cada vez mais as políticas de privatização nas instituições públicas, a reprimir e criminalizar os movimentos populares que resistem à política neoliberal, e a impor uma ideologia de insensibilidade, de individualismo e de cooperação em prol do mercado.

A construção e permanência da política neoliberal perpassa pelo aceite e doutrinamento das recomendações dos organismos multilaterais, essas já denunciadas por Marcelo Dias Carcanholo (2000), por meio da reunião em 1989 do FMI, BID e Banco Mundial que estabeleceram dez áreas de ação dessa política global: “ disciplina fiscal, priorização dos gastos públicos, reforma tributária, liberalização financeira, regime cambial, liberalização comercial, investimento direto estrangeiro, privatização, desregulação e propriedade intelectual”' (p. 25).

Os governos populares eleitos no Brasil de Luiz Inácio Lula da Silva (2003 a 2007 e de 2008 a 2011) e de Dilma Vana Rousseff (2011 a 2014 e de 2014 a 2016) por mais que ainda estivessem presos à política neoliberal, representavam contraditoriamente uma ameaça futura aos encaminhamentos mercadológicos, frente aos interesses populares e na permissão de liberdade dos movimentos sociais organizados. O perigo da não efetivação e até mesmo do retrocesso dessa política fez com que se orquestrasse um golpe ao governo de Dilma Rousseff, na forma de impeachment (2016). Anterior e concomitante a isso, eclodia nas esferas municipal, estadual e federal as ideias do movimento criado em 2004 por Miguel Nagib, transformado depois em 
associação (2015), da Escola sem Partido, cujo crescimento no país demonstrou o peso do conservadorismo, que se contrapôs à liberdade de cátedra do professor, à pedagogia libertadora de Paulo Freire e às discussões de conteúdo político e de cidadania na sala de aula.

Após o impeachment da Ex-presidente da República Dilma Rousseff em 2016, houve um maior recrudescimento dos pressupostos neoliberais e do conservadorismo, defendido principalmente pela extrema direita brasileira. As consequências do neoliberalismo no sistema educacional passaram a aspirar inúmeras formas, como: 1) políticas educacionais austeras e reformas baseadas na competitividade e nos imperativos financeiros, e que aumentam as desigualdades sociais; 2) controle do professor e medidas de responsabilização, combinadas com aumento da carga de trabalho e significativa insegurança profissional; 3) ataques invisíveis e oportunistas às missões educacionais, fundamentalmente democráticas, e ao papel emancipatório das escolas.

No Brasil, como em outros lugares, o neoliberalismo é indissociável do estabelecimento de uma política social, que visa facilitar a prosperidade do mercado, por meio de um projeto de Estado autoritário e neoliberal que faz, sobretudo, a atividade econômica justificativa última para a ação política, a fonte primária de sua legitimação, o que o Presidente Jair Bolsonaro anunciou desde o início do seu mandato. Em face disso, as relações dialógicas sobre a gestão democrática escolar brasileira precisam considerar essas mudanças, uma vez que essas sucessivas e rápidas mudanças, observadas por meio da globalização e advindas da redução estatal, propendem requerer do meio social que a escola assuma a responsabilidade e encontre soluções viáveis para seus impasses.

Assim, no espaço da educação, os resultados dessas transformações, que transcorreram sob o gerenciamento do neoliberalismo, representam uma redução do envolvimento do poder estatal na plena realização dos serviços públicos. Dessa forma, a democracia e seus princípios de autonomia e envolvimento de todos os partícipes do âmbito escolar conseguem mais coragem e otimismo, apesar de estarem mergulhados em antagonismos presentes no real.

De acordo com Mousquer (2003), nos últimos anos do século XX, mediante o paradigma predominante do liberalismo, as perspectivas elaboradas a respeito da democracia foram deixadas de lado, uma vez que se imaginava que não são as conjunturas basilares da democracia que a motivavam, mas que todo o país se torna democrático por meio da ação democrática. A partir da desconstrução do chamado "Estado Providência" e eliminação das políticas sociais, abriram-se as portas para os debates sobre o conceito de democracia.

A princípio, os diálogos travados sobre a democracia precisam determinar seus valores essenciais. Neste trabalho, compreendem-se como valores essenciais as distinções que possibilitam determinar que uma ação, instituição ou acontecimento possua ou não uma natureza democrática. Ao estudar a democracia em sua etimologia como sendo o "o poder que emana do povo", mesmo compreendendo que provavelmente essa maneira de exercer o governo, assim como recomenda este significado, não encontre sua efetivação por meio da prática, pode ocasionar desapontamento entre os que nela acreditam com plena convicção.

Há uma vulgarização da palavra democracia, apesar de todos os diálogos realizados sobre ela. Assim sendo, a democracia pode ser empregada pelas mais variadas correntes de pensamento, abrangendo os mais tradicionais, bem como os esquerdistas reacionários. Atualmente, países que, por meio de procedimentos bélicos se contrapõem a formas de pensamento contrários aos estabelecidos pelo governo, promovem invasões territoriais sobre outros países e são comercializados mundialmente como modelos de lugares onde a democracia prevalece. Ou seja, torna-se ineficaz proclamar que democracia ou que uma nação democrática é aquela que está atenta 
aos interesses comuns da população, mas é necessário compreender o modo pelo qual estes interesses são recebidos, sistematizados e colocados em prática no decurso da história.

Para Bobbio, o gérmen destes propósitos ou princípios morais é a igualdade, não somente relativa à justiça, a qual é assimilada nas constituições que defendem a liberdade de pensamento, mas a igualdade social e econômica. Dessa forma, a partir do esclarecimento destes propósitos ou princípios, passa-se de uma compreensão protocolar de democracia para uma compreensão fundamental sobre o conteúdo desta configuração. Em essência, uma democracia, uma organização ou um Estado democrático são aqueles governados, administrados ou dirigidos em favor da conservação de valores que levem em consideração os interesses da população, pois este anseio geral não pode ser mesclado de desejos e cobiças particulares.

A compreensão de democracia possui uma estreita relação com a teoria roussoniana sobre a democracia. Esta teoria que defende o pensamento de igualdade que suscita a democracia encontra a sua efetivação na concepção dos interesses do povo. Uma democracia perfeita precisaria ser, simultaneamente, protocolar e fundamental, o que até o presente momento não se sucedeu. Pode-se argumentar que o que acontece é a composição de ferramentas por meio das quais a somatória de desejos particulares ocasiona uma aspiração comum.

\section{A RELEVÂNCIA DO ESPÍRITO DEMOCRÁTICO}

Atualmente, a democracia que a população vivencia é decorrente da composição do Modelo Democrático de Schumpeter, o qual possui as seguintes características:

a democracia é um mecanismo para escolher e autorizar governos, a partir da existência de grupos que competem pela governança, associados em partidos políticos e escolhidos por voto; a função dos votantes não é a de resolver problemas políticos, mas de escolher homens que decidirão quais são os problemas políticos e como resolvê-los - a política é uma questão das elites dirigentes; a função do sistema eleitoral, sendo a de criar o rodízio dos ocupantes do poder, tem como tarefa preservar a sociedade contra os riscos da tirania; o modelo político baseia-se no mercado econômico fundado no pressuposto da soberania do consumidor e da demanda que na qualidade de maximizador racional de ganhos, faz com que o sistema político produza distribuição ótima de bens políticos; a natureza instável e consumidora dos sujeitos políticos obriga a existência de um aparato governamental capaz de estabilizar as demandas da vontade política pela estabilização da vontade geral, através do aparelho do estado, que reforça acordos, aplaina conflitos e modera aspirações (CHAUÍ, 1997. p. 138).

No livro "A Democracia Liberal", McPherson (1978) realiza críticas veementes sobre o modelo de Schumpeter. Na obra, ele assegura que o referido modelo é diversificado e elitista, visto que presume que é o meio social que deve seguir o ritmo imposto pela democracia liberal. É uma sociedade diversificada e o encargo político principal é de responsabilidade das elites que governam. Assim, são notórias duas contradições no modelo schumpeteriano.

A primeira é a estimativa de que as necessidades do meio social são imóveis ou alicerçáveis pelo poder estatal, para preservar a operacionalização desta estrutura na qual o Estado é o consolidador dos interesses comuns da população. A segunda é o da primazia daquele ou daquela que consome. Portanto, não é possível em uma economia de oligopólios, onde o mercado é quem 
realizará e fará a supervisão das necessidades, liberar a escolha, uma vez que cumpre ao consumidor unicamente a oportunidade de escolha entre duas alternativas determinadas pela atividade de compra e venda de produtos e de serviços.

A partir da observação crítica acerca do modelo democrático de Schumpeter, percebem-se as controvérsias de um modelo que se reporta ao governo do povo, mas no qual o povo, em um momento defensor de uma aplicabilidade do sistema, ademais de uma autonomia do livre comércio, é marginalizado frente às decisões importantes para a consolidação de uma democracia autêntica e que alcance a todos. Um exemplo disso é o setor da educação, a qual tem sido um dos setores mais afetados pelas políticas neoliberais do governo Jair Bolsonaro. A convocação de uma greve nacional na educação seguiu-se ao anúncio do governo Bolsonaro sobre a implementação de medidas adicionais para reduzir o investimento público em educação, que já é insuficiente. A reestruturação do Fundo de Educação Básica (FUNDEB), instituído pela Emenda Constitucional n 108, de 27 de agosto de 2020, e regulamentado pela Lei $\mathrm{n}^{\circ} 14.113$, de 25 de dezembro de 2020, vem prejudicando, entre outras coisas, programas de financiamento de transporte e alimentação escolar, livros didáticos, formação de profissionais em educação, construção e reforma de escolas.

Em contraposição a este modelo, McPherson apresenta como proposta a Democracia Participativa. Esse modelo possui as seguintes pré-condições:

a) mudança da consciência popular, que passa a ver-se não mais como consumidora, mas agente e executor que desfruta de suas próprias decisões. Trata-se do sentimento de comunidade; b) grande diminuição da atual desigualdade social e econômica, na medida em que a desigualdade é o motor da coesão da ordem capitalista, pois impede a participação político partidária e é o sustentáculo da ordem vigente; c) estimular procedimentos pelos quais se viabilizem as propostas de Marx [...] e Stuart Mill [...] numa democracia participativa. Este procedimentos seriam: associações de bairro e de vizinhança, lutas pela melhoria da qualidade de vida, pela liberdade de expressão, pelos direitos de minorias, pela co-gestão das empresas pelos trabalhadores [...]; d) enfatizar o peso e o ônus social trazido pelo crescimento do capitalismo, as dúvidas quanto às capacidades do capitalismo financeiro para satisfazer necessidades aumentadas pela desigualdade, a consciência dos prejuízos causados pela apatia política (CHAUÍ, 1997, p. 139 - 140 ).

A característica de ambos os modelos liberais democráticos é o de considerar rigorosamente a democracia enquanto um paradigma político, institucional, que encontra repouso sobre conjecturas compreendidas como circunstâncias sociais vivenciadas pela democracia. Tais conjecturas políticas e sociais idealizam a democracia como uma maneira de convivência social expressa somente no momento da escolha dos representantes do povo e em sua natureza emblemática. Culturalmente, entende-se a democracia como o suporte da igualdade entre as pessoas, autoridade do povo, cumprimento das demandas presentes na Constituição, respeito à vontade da maioria, mas, do mesmo modo, dos direitos da pequena parcela da população e liberdade de pensamento.

No entanto, fica claro que a vulnerabilidade democrática causa espanto perante a globalização capitalista, como no caso dos Sindicatos de professores no Brasil. Em 2019, os sindicalistas da educação foram rapidamente agregados a outros setores, após uma série de declarações de Bolsonaro contra a democracia e o anúncio de uma nova lei (Lei da Liberdade Econômica) que iria minar os direitos dos trabalhadores, em particular através da legalização do 
trabalho precário ou da tributação dos desempregados. Além disso, os planos do governo para a reforma do setor público desmantelarão violentamente muitas das conquistas e direitos dos trabalhadores do setor público.

Embora falem sobre a coletividade, na democracia representativa as providências tomadas e as escolhas partem não a partir desta coletividade, mas exclusivamente por uma aristocracia eleita com esta intenção. Apesar dos muitos problemas de harmonização deste modelo de governo, com os procedimentos participativos e de formulação dos interesses comuns, a democracia representativa é suprema. Sobre isso, Bobbio (2000) argumenta que essa democracia venha a ser a única em pleno andamento e que possibilita o desenvolvimento da sociedade. Diante disso, "é possível à sobrevivência de um Estado democrático numa sociedade não democrática? [...] A democracia política foi e é até agora necessária para que um povo não seja governado despoticamente. Mas é também suficiente?” (BOBBIO, 1997, p. 156).

Bobbio realiza uma reflexão crítica sobre a efetivação e a legitimidade de um Estado pôrse como estabelecido, com base democrática, dentro de uma comunidade social supressiva e administrada pelos interesses exclusivos do mercado e sua natureza corporativista. Em uma sociedade capitalista, a democracia é considerada muito mais enquanto um instrumento ideológico, por meio do qual os sujeitos são conduzidos a um ceticismo, decorrente da carência de instrução política, ou a uma compreensão simplória de que possui participação efetiva nas decisões tomadas em benefício do povo. Isso explica a ascensão dos ideais da extrema direita na Eleição Presidencial Brasileira em 2018, simbolizada pelo então candidato Jair Bolsonaro.

Faz-se necessário evidenciar que, apesar das inúmeras limitações enfrentadas, não se pode comparar a democracia com a monarquia, a autocracia, principalmente com o totalitarismo. Segundo Bobbio (2000, p.22), esse denominado "conjunto de regras e procedimentos para a formação de decisões coletivas", tornou possível um significativo desenvolvimento da participação dos envolvidos. No entanto, o contrário também é verdadeiro, uma vez que facilitou a falta de interesse relativos aos assuntos de suma importância da comunidade social, assim como o desinteresse político. "Se Bobbio crê em sua afirmação de que a democracia é subversiva e difícil, há de concordar que as classes dominantes façam o possível e o impossível para controlar e desmantelar os efeitos das práticas democráticas" (CHAUÍ, 1997, p. 189).

Assim sendo, a elaboração e o desenvolvimento da democracia encaram inúmeros desafios, impasses, oriundos dos instrumentos fabricados para a disseminação, e conservação de uma elite governante. É de grande importância ações democráticas que se relacionem com as necessidades da coletividade, assegurando o compromisso participativo nas decisões tomadas. A escola aparece como ambiente excepcional para a elaboração e o estabelecimento destas ações em seu cotidiano pedagógico.

As transformações pelas quais o espaço escolar precisará passar, a fim de que os comportamentos egoístas, que comprometem o envolvimento participativo, sejam suprimidos pelo bem da coletividade, precisam se estruturar com base na acessibilidade que a instituição de ensino possui atualmente para sistematizar-se. No entanto, há percursos que demandam da escola uma educação de qualidade e um melhor desempenho na formação de um novo profissional, crítico e que possua interesses e aptidões políticas e criativas. Dessa maneira, quanto mais autonomia a escola possuir, maior fica a quantidade de demandas a serem cumpridas.

Os principais estudiosos que abordam o assim denominado modelo neoliberal são: Friederich Hayek e Milton Friedman. Partindo dos escritos destes notáveis pensadores, se intenciona ponderar sobre esse modelo. Tais estudiosos citados refletem criticamente as premissas 
de intervenção do Estado, seja esta premissa oriunda do modelo de "Estado Benfeitor" e Keynesiano, bem como oriunda do marxismo.

No bojo dessa compreensão crítica procura-se abranger um conjunto de significados mais evidentes do modelo neoliberal, o qual, de acordo com McPherson, representa "uma elaboração teórica com vistas a exibir as relações reais, subjacentes às aparências, entre os fenômenos ou no seio dos fenômenos em estudo" (apud BIANCHETTI, 2001, p. 70). Em outras palavras, o interesse é essencialmente reorganizar a coerência que estabelece relações dos significados que sustentam o denominado "modelo de sociedade".

\section{A EDUCAÇÃO BRASILEIRA E O DESENVOLVIMENTO DO ESTADO DEMOCRÁTICO}

Para entender a conjuntura contemporânea da educação brasileira, assim como o caminho percorrido pela democracia no âmago desta conjuntura, é necessário observar as mudanças políticas, sociais e econômicas ocorridas nas últimas décadas. Analisa-se o Brasil como um país democrático em processo de construção e desenvolvimento, pois a maioria dos principais baluartes do cenário político contemporâneo mostrou apoio ao governo totalitário que marcou profundamente a história brasileira em anos passados.

De 1964 a 1985, o cidadão brasileiro vivenciou mais de duas décadas de opressão, momento em que a democracia ficou imensamente debilitada, e onde o Estado fora sistematizado mediante atos institucionais. Estes atos lesionavam com profundidade os direitos da população. Segundo Rossi (1984, p. 32), o Ato Institucional n5 (AI5) caracterizou "o fantástico mecanismo repressivo que seria montado nos anos subsequentes", limitando completamente toda e qualquer condição favorável de envolvimento da população no estabelecimento de políticas públicas que assegurassem os direitos fundamentais do ser humano como a educação.

No momento em que ocorreu o processo de abertura política, o regime militar, ainda assim, fez uso de inúmeros procedimentos estratégicos para comprimir as demandas existentes no dia-adia da população brasileira que tomava as ruas, com a intenção de exigir o término deste acontecimento histórico, assinalado pelo aperto do salário, pelo crescimento da dívida externa, pela contenção às prerrogativas de cunho político, pela natureza autoritária, pela repreensão ideológica, entre tantas outras formas de massificação política.

Supervisionada pela comarca superior do comando estabelecido, uma mudança democrática pôde contar com uma grande quantidade de ferramentas de limitação do seu caminho, a fim de que se efetivassem as determinações da "abertura política", realizando com o que evidencia Weffort (1984), "não somos, no Brasil, apenas herdeiros de atitudes ambíguas e cínicas em relação à democracia. Somos também herdeiros de uma verdadeira cultura de golpes" (p. 42). Diante disso, Paro (2002, p. 99) recomenda a importância de o cidadão possuir consciência política:

A tomada de consciência política reveste-se, assim, da importância fundamental para a participação dos componentes da classe operária no processo de criação de um sistema hegemônico. Através dela, eles se percebem ao mesmo tempo como sujeitos da história e como membros do único grupo social com condições de assumir a direção de um movimento radical de transformação social.

Logo após 1988, em contraposição ao momento histórico que anunciou o regime ditatorial militar, o governo brasileiro presenciou uma outra época histórica, a qual foi assinalada pela 
oportunidade de efetivar o Brasil como um país democrático e de direito, concretizado na Constituição Federativa Brasileira, possuindo na composição dos conselhos, uma das condições mais favoráveis para estabelecer a democracia no país.

Os conselhos populares foram propostas dos setores da esquerda ou de oposição ao regime militar, e surgiram com papéis diversos tais como: organismos do movimento popular atuando com parcelas de poder junto ao executivo (tendo a possibilidade de decidir sobre determinadas questões de governo); organismos superiores de luta e de organização popular; gerando situações de duplo poder; organismos de administração municipal criados pelo governo para incorporar o movimento popular ao governo, no sentido de assumirem tarefas de aconselhamento, deliberação e/ou execução (VALE, 2001, p. 75).

Apesar de transpassadas por supervisões, como no caso da "abertura política", reconhecese que as transformações aconteceram, como o estabelecimento dos conselhos gestores, os quais segundo Gohn (2001, p. 70) representam a "possibilidade de participar da gestão dos negócios públicos criados por leis originárias do poder Legislativo, surgidos após pressões da sociedade civil", em sua grande maioria com recursos particulares e essenciais, para colocar em prática os projetos permitidos pela organização social. Na educação, as vitórias conquistadas na Constituição Federal, promulgada em 1988, materializaram a oportunidade de a instituição escolar ser objeto de reflexão crítica e, dessa forma, ser organizada pela sua comunidade que apontaria as responsabilidades sociais da escola em sua complexidade pedagógica, administrativa, econômica e cultural. Como bem mencionam Gadotti e Romão (1997, p. 16):

A Constituição promulgada em 1988 é o principal fundamento da gestão democrática do ensino público, pois, além de prevê-la expressamente no artigo 206, institui a 'democracia participativa' e possibilita o exercício 'direto' do poder (art. $1^{\circ}$ ), e o 'regime de colaboração' entre União, Estados e Municípios (Art. 211).

Este importante documento determina que a educação tem como um de seus princípios a gestão democrática (inciso VI, do Art. 206), corroborando com as condições igualitárias para o acesso e a permanência no ambiente escolar, a prerrogativa e o parâmetro de qualidade, a diversidade de pensamentos e de compreensões de ensino, o reconhecimento social dos educadores e educadoras, bem como a oportunidade de os municípios formularem e estabelecerem suas estruturas pedagógicas, as quais determinam as políticas de coparticipação entre os organismos estatais, que garantam, em comunhão, a expansão da educação indispensável ao sujeito.

No entanto, a realidade histórica e política brasileira nos anos 1990 é assinalada pelo estabelecimento do neoliberalismo e da sua forma de pensamento, suas repercussões para a classe trabalhadora. Em face dessa conjuntura, esse momento histórico é reconhecido pela disseminação das práticas pedagógicas que desenvolvem a troca da responsabilidade estatal pela atividade empresarial, no que diz respeito ao campo dos serviços ligados à sociedade e, consequentemente, ao campo da educação. A atenção no estabelecimento do modelo neoliberal, nesta década, suscita uma permutação de incumbências com a educação e, do mesmo modo, com a escolarização do povo, especialmente da classe trabalhadora. Este interim, retira o Estado da colocação de primeira organização encarregada de assegurar a educação de cada cidadão brasileiro, de acordo com as premissas determinadas na legislação contemporânea. 


\section{A DESCENTRALIZAÇÃO NO CONTEXTO EDUCACIONAL}

A descentralização configura-se como uma das principais finalidades das reorganizações estatais do neoliberalismo, oriunda das observações críticas referentes ao assim denominado inchaço estatal de Bem-Estar-Social. A discussão entre a centralização e a descentralização das políticas de educação movimenta-se paralelamente ao que Romão (1997) leva em consideração como desconcentração, isto é, a desconcentração é nada mais nada menos do que uma combinação tecnocrática da centralização.

Assim sendo, vivencia-se a um período de ausência de responsabilidade estatal com o ensino público, segundo as normas das recomendações das entidades mundiais, as quais aumentaram o seu fortalecimento mediante a denominada "crise do estado de bem-estar social" e as decorrentes otimizações das proposições do neoliberalismo, dos anos 1990.

De acordo com Neves (2000), o envolvimento participativo dos organismos internacionais no estabelecimento das políticas públicas de educação no Brasil, particularmente do Banco Mundial e do FMI, inicia desde os anos 1950, primeiramente com a permuta entre os professores brasileiros e norte-americanos. Em seguida, a partir dos anos 1960, por meio das convenções econômicas e da Agência para o Desenvolvimento Internacional do Departamento de Estado dos estados Unidos da América (USAID), no contexto da "Aliança para o Progresso". Finalmente, a partir dos anos 1970, com as notáveis aplicações de capital em projetos educacionais.

Esse envolvimento possui uma ampla dimensão a partir dos anos 1990, momento em que o Brasil recebe o convite para integrar a Conferência Mundial de Educação para Todos, sediada em Jomtien, Tailândia, orientada pela Organização das Nações Unidas para a Educação, Ciência e Cultura - UNESCO, pelo Fundo das Nações Unidas para a Infância - UNICEF, pelo Programa das Nações Unidas para o Desenvolvimento - PNUD e pelo Banco Mundial. Os debates realizados na ocasião prosseguiram em direção ao estabelecimento de políticas de ajustamento para os países limítrofes ao desempenho internacional do mercado, no qual se tem a educação como um fator que torna possível o desenvolvimento econômico e a minimização das misérias sociais.

A Conferência Mundial de Educação para Todos teve como resultado a formulação de documentos de dimensão internacional. No Brasil, essas recomendações culminaram na realização da Conferência Nacional de Educação para Todos, em 1994, bem como no decorrente Plano Decenal de Educação para Todos. Em 1999, estabelecido no governo FHC, o Programa Educação para Todos.

A nova ordem econômica mundial vem ocasionando transformações impressionáveis nas diretrizes de educação do Brasil, as quais fundamentam-se nas premissas de privatização e desnacionalização, tornando possível o estabelecimento de projetos e programas comprados dos países considerados de primeiro mundo enquanto parâmetro a ser acompanhado. Dessa forma, tem início um período de comercialização educacional.

Os anos 1980 e 1990 são marcados pela incorporação do empresariado brasileiro nos assuntos relacionados à educação, objetivando uma ampla atualização e capacitação profissional. Proclamando o discurso da internacionalização da educação básica, a classe média fabril passa a controlar os enunciados da classe trabalhadora, porém sem colocar em prática atitudes que tenham como finalidade responder aos interesses e necessidades ponderados por essa classe. Nessa mesma época, o empresariado exige seu envolvimento funcional no estabelecimento das políticas de educação, procurando rendimentos súbitos (RODRIGUES, 1998). Sobre as reformas ocorridas no 
capo da educação na década de 1990, Dourado (2002, p. 236) destaca um complicador a este panorama na conjuntura brasileira ao mencionar que:

No caso brasileiro, demarcado historicamente por um Estado patrimonial ${ }^{2}$ as arenas tradicionais do poder político sofrem alguns ajustes na direção da mercantilização das condições societais, agravando ainda mais o horizonte das conquistas sociais, ao transformar direitos em bens, subjugando o seu usufruto ao poder de compra do usuário, mercantilizando as lutas em prol da cidadania pelo culto às leis do mercado.

A descentralização, enquanto resultado das reformas neoliberais da década de 1990, mostra pormenores diversificados, de desenvolvimento do prenúncio privatista e comercial na educação ou de desenvolvimento de políticas que promovam a democracia, com amplo compromisso participativo do cidadão na realização dos serviços de ordem pública. Diante disso, a gestão democrática na escola pública pode ser efetivada.

A Lei Darcy Ribeiro ou Lei de Diretrizes e Bases da Educação Nacional (LDB), 9394/96 (Art. 14 e incisos e Art. 15) acentua a gestão democrática, baseada na liberdade educativa, administrativa e econômica, como fundamento da educação brasileira e, ressalta que os sistemas de ensino precisam garantir esse dispositivo. Assim, a lei conjectura que os sistemas de ensino estabeleçam as diretrizes da gestão democrática, levando em consideração que todos os componentes da comunidade pedagógica tenham participação nos contínuos níveis de liberdade educativa, administrativa e econômica já uniformizadas pelo sistema.

A gestão democrática exposta no Plano Nacional de Educação - PNE (2001-2010 e 20142024) possui significantes diferenças que envolve status e dimensões que foram alcançadas no PNE (2014-2024). Enquanto no PNE (2001-2010) a gestão democrática foi tratada com timidez, cuja implantação estava descompromissada do Estado, no PNE (2014-2024) esta tornou-se princípio (inciso VI) dentre as diretrizes do Plano expostas no artigo $2^{\circ}$. Esse Plano reforça a importância da participação coletiva representativa de estudantes, educadores, pais e responsáveis por meio das associações, grêmios, conselhos, fóruns e no planejamento global da escola, por meio da elaboração do Projeto Político Pedagógico. Tais discussões para a efetivação da gestão democrática foram sistematizadas no Eixo II, pelo documento final elaborado pela CONAE (2010). Por outro lado, existe a fragilidade do Estado na constituição da gestão democrática pela associação desta ao financiamento da educação e na descentralização de sua responsabilidade junto às escolas. O exíguo prazo planejado de 2 anos para a efetivação da gestão democrática na educação demonstra a ausência de uma realidade afirmativa na concretização da Meta 19, no PNE (2014-2024) e suas estratégias. Nesse aspecto, as bases legais para a consolidação da gestão democrática não se constituíram em avanços mais práticos em sua implementação nas escolas brasileiras.

Assim, a legalidade dos sistemas educacionais não assegura eficazmente o surgimento e conservação da democracia em nenhum ambiente escolar. No entanto, são as convivências que se constituem no cerne dos estabelecimentos de ensino que assegurarão ou não o desenvolvimento da democracia. Do mesmo modo, são as maneiras de efetivação da legalidade que podem assegurar uma determinante visão democrática da educação.

Já que a lei [...] é uma conquista de tantas lutas, de tantos anos, e se faz pela primeira vez na história. Pode ser entendido no sentido de que as leis não são auto-aplicáveis, elas precisam ser assumidas por políticas que as viabilizem. Se desconhecemos a viabilização dessas leis e nós, enquanto povo, não nos 
acostumamos a exigir a execução, elas ficarão engavetadas. Mas se nós lutarmos - professores, educadores - teremos um instrumento legal fortíssimo, que poderá dar resultado (REDIN, 2001, p. 12).

É convincente a democratização que proporciona a concepção de uma lei, no entanto não é possível que ela, sozinha, torne mais democrática as relações sociais de poder, principalmente na escola. Em outras palavras, a lei é uma ferramenta que auxilia na criação de ambientes de envolvimento coletivo, porém torna-se inviável compelir uma instituição a ser democrática.

\section{CONSIDERAÇÕES FINAIS}

A compreensão dos fundamentos históricos, políticos, econômicos e culturais que alicerçam a história contemporânea da nossa sociedade se faz primordial, principalmente nestes tempos sombrios que permeiam os alicerces do Estado Democrático Brasileiro, iniciado com impeachment da primeira Presidente mulher do Brasil em 2016 e que trouxe os retrocessos à sociedade brasileira e à educação, principalmente com o presidente Jair Bolsonaro. Isso se traduz em um instrumento de enorme relevância para entender a razão pela qual muitos abrem mão do seu direito, em benefício de outro que possui o conhecimento, ou uma função destacada na hierarquia da escola. Tal compreensão é uma atividade imprescindível para que os sujeitos planejem, com cuidado e responsabilidade, o desenvolvimento do ambiente escolar, no qual a democracia possa se efetivar concretamente.

Ainda no contexto social vivenciado pela educação brasileira, o desenvolvimento da democracia caminha vagarosamente e não existe a prerrogativa de que alcançará resultados favoráveis dentro da escola, absorvida pelas características do ensinamento técnico e centralizador. Diante disso, a democracia que necessita permear os vínculos entre professores e estudantes, enquanto sujeitos em constante relação, precisa adentrar no meio destas convivências pedagógicas, e se constituir em práxis pedagógica.

Um espaço escolar democrático comunga do ideal de participação, e essa união é planejada a partir da construção de uma instituição educativa viável e essencial para a maioria da população. Essa construção decorrerá no momento em que escola e comunidade ambicionarem as transformações possíveis e importantes para toda a coletividade, considerando os problemas e a maneira de solucioná-los.

Enfim, todos os membros que integram o meio escolar assumem uma responsabilidade de suma importância e complexa, uma vez que possuem o compromisso com o futuro da escola pública e a incessante batalha pela cidadania. Em face disso, a democracia se torna um assunto que incita muitos questionamentos e abre as portas na busca de soluções que estejam em conformidade com os interesses contemporâneos. Isso acarreta conscientização, senso de participação e mudanças de paradigmas. 


\section{REFERÊNCIAS}

BIANCHETTI, Lucídio. Da chave de fenda ao laptop, tecnologia digital e novas qualificações: desafios à educação. Petrópolis: Vozes, 2001.

BOBBIO, Norberto. Estado, governo, sociedade: para uma teoria geral da política. 6. ed. Rio de Janeiro: Paz Eterna, 1997.

BOBBIO, Norberto. Igualdade e liberdade. 4. ed. Rio de Janeiro: Ediouro, 2000.

BRASIL. Lei de Diretrizes Básicas da Educação Nacional - 9394/96, Senado, Brasil.

BRASIL. Constituição Federativa do Brasil, 1988.

BRASIL. Plano Nacional de Educação, 2001-2010.

BRASIL. Plano Nacional de Educação, 2014-2024.

BRASIL. CONAE - Conferência Nacional de Educação: construindo o sistema nacional articulado de educação: o plano nacional de educação, diretrizes e estratégias de ação. Brasília: MEC, 2010.

CARCANHOLO, Marcelo Dias. Neoliberalismo e o consenso de Washington: a verdadeira concepção de desenvolvimento do governo FHC. In: Neoliberalismo: a tragédia do nosso tempo. 2. ed. São Paulo: Cortez, 2000.

CHAUI, Marilena. Cultura e democracia. $7^{a}$ ed. São Paulo: Cortez, 1997.

CHOMSKY, Noam. O lucro ou as pessoas. Tradução Pedro Jorgensen Júnior. Rio de Janeiro: Bertrand Brasil, 2002.

DOURADO, Luiz Fernandes. Reforma do Estado e as políticas para a educação superior no Brasil nos anos 90. Educação e Sociedade, Campinas, v. 23, n. 80, 2002. Disponível em: $<$ http://www.scielo.br/scielo.php?script=sci_arttext\&pid=S0101-

73302002008000012\&lng=pt\&nrm=iso $>$.Acesso em: 02 janeiro de 2018.

GADOTTI, Moacir; ROMÃO, Jose Eustaquio (orgs). Autonomia da escola: princípios e propostas. 2 ed. São Paulo: Cortez, 1997.

GOHN, Maria da Glória Marcondes. Conselhos gestores e participação sóciopolítica. São Paulo: Cortez, 2001.

HARVEY, David. O neoliberalismo: história e implicações. São Paulo: Loyola, 2012.

McPHERSON, Crawford Brough. A democracia liberal. São Paulo: Zahar. 1978.

MOUSQUER, Maria Elizabete. Paradoxos da democracia: um estudo sobre normatividade e possibilidade no campo da gestão democrática do Ensino Público. 2003. 268f. Tese (Doutorado em Educação) - Universidade Federal do Rio Grande do Sul, Porto Alegre.

NEVES, Lúcia Maria. Brasil 2000: nova divisão do trabalho na Educação. 2ed. SP: Xamã, 2000.

PARO, Vitor Henrique. Administração escolar: introdução crítica. 11 ed. São Paulo: Cortez, 2002.

REDIN, Euclides. Não se faz Universidade para satisfazer o mercado de trabalho: a paixão de aprender. Porto Alegre, no 14, p. 10-3, nov. 2001.

RODRIGUES, José dos Santos. O moderno príncipe industrial: o pensamento pedagógico da confederação nacional da indústria. Campinas: Autores Associados, 1998.

ROMANELLI, Otaíza de Oliveira. História da educação no Brasil: 1930/1973. Petrópolis: Vozes, 1984. 
ROMÃO, Jose Eustaquio. Diretores escolares e gestão democrática da escola. In: GADOTTI, Moacir; (orgs). Autonomia da escola: princípios e propostas. 2 ed. São Paulo: Cortez, p. 91-102. 1997.

ROSSI, Clóvis. Militarismo na América Latina. 2 ed. São Paulo: Brasiliense, 1984.

SNYDERS, Georges. Escola, classe e luta de classe. Rio de Janeiro: Moraes Editores, 1981.

TOURAINE, Alain. O que é a democracia? Petrópolis: Vozes, 1996.

VALE, Ana Maria do. Educação popular na escola pública. 2 ed. São Paulo: Cortez, 2001.

WEFFORT, Francisco. Por que democracia? São Paulo: Brasiliense, 1984.

Submetido em maio de 2020

Aprovado em setembro de 2021

\section{Informações do(a)(s) autor(a)(es)}

Pérsida da Silva Ribeiro Miki

Universidade Federal do Amazonas

E-mail: persidamiki@gmail.com

ORCID: https://orcid.org/0000-0003-3684-681X

Link Lattes: http:// lattes.cnpq.br/7439443236145560

Carlos César Macêdo Maciel

Universidade Federal do Amazonas

E-mail: carlosmacielufam@gmail.com

ORCID: https://orcid.org/0000-0002-6722-6712

Link Lattes: http://lattes.cnpq.br/4475656102366988 